\title{
Long-Term Effects of Hypoxia-Reoxygenation on Thioredoxins in Rat Central Nerv- ous System
}

\author{
Otero-Losada $\mathrm{M}^{1}$, Canepa $\mathrm{L}^{2}$, Udovin $\mathrm{L}^{1}$, Kobiec $\mathrm{T}^{1,3}$, Toro-Urrego $\mathrm{N}^{1}$, Kolliker Frers $\mathrm{RA}^{1}$ and Capani $\mathrm{F}^{1, *}$ \\ ${ }^{I}$ Institute of Cardiological Research. University of Buenos Aires. National Research Council. ININCA.UBA-CONICET. Buenos Aires, \\ Argentina; ${ }^{2}$ Departamento de Biología, Universidad Argentina John Kennedy (UAJK), Buenos Aires, Argentina; ${ }^{3}$ Centro de \\ Investigaciones en Psicología y Psicopedagogía (CIPP), Pontificia Universidad Católica Argentina, Buenos Aires, Argentina
}

\begin{abstract}
Oxidative stress induced by the oxidative pathway dysregulation following ischemia/reperfusion has been proposed as an important cause of neuronal death and brain damage. The proteins of the thioredoxin $(\operatorname{Trx})$ family are crucial mediators of protein function regulating the intracellular hydrogen peroxide levels and redoxsensitive post-translational protein changes. This study evaluates the long-term effects of common carotid artery ligation-induced ischemia/reperfusion on the protein expression and distribution of fourteen members of the Trx family and related proteins (Grx1, Grx2, Grx3, Grx5, Prx1, Prx2, Prx3, Prx4, Prx5, Prx6, Trx1, Trx2, TrxR1, TrxR2) in the most hypoxia susceptible rat brain areas, namely, cerebellum, corpus striatum, and the hippocampus. The thioredoxin proteins displayed a complex, cell-type, and tissue-specific expression pattern following ischemia/reperfusion. Even 60 days after ischemia/reperfusion, Western blot analysis showed a persistent expression of Trx 1 and Grx2 in several brain areas. Thioredoxins might participate in the long-term restoration of redox signaling, and the recovery of the affected tissues.
\end{abstract} Received: October 30, 2019
Accepted: December 09,2019

DOI:

Keywords: Common carotid artery occlusion, thioredoxin family, CNS, hypoxia-ischemia.

\section{INTRODUCTION}

Brain damage resulting from an ischemic event in the fetus or newborn infant (also known as perinatal asphyxia, PA) remains a major cause of neonatal death and neurological deficits in children. Cerebral palsy, mental retardation, and epilepsy are among the most common complications of perinatal asphyxia [1-4]. The incidence of severe perinatal asphyxia is estimated to about 1:1000 live births in developed countries, and 5-10:1000 live births in developing countries [5]. This clinical picture has been largely reproduced, exposing rodents to an oxygen-deprived atmosphere on post-natal day seven after the right common carotid artery (CCA) ligation [3, 6-9]. By post-natal day seven, the rat brain is histologically similar to that of a 32-34 week gestation human fetus or a newborn infant, e.g., the cerebrocortical neuronal layering is complete, the germinal matrix shows involution, and the white matter has undergone little myelination [10].

Reactive oxygen species (ROS) are a likely cause of neuronal death and brain damage after ischemia/reperfusion [11]. Aerobic metabolism renders oxygen free radicals in the cytoplasm and mitochondria [12], physiologically involved in specific signalling processes such as developmental regulation, cell proliferation, differentiation, and apoptosis. Locally produced, and swiftly degraded by specific enzymes, ROS interact with specific target molecules [12]. However, excessive production of ROS can lead to oxidative and irreversible damage to macromolecules and has been linked to various pathological conditions like ischemia-reperfusion $[11,13,14]$.

Several therapeutic approaches have been proposed to neutralize ischemia-induced ROS like the administration of degrading

*Address correspondence to this author at the Institute of Cardiological Research. University of Buenos Aires. National Research Council. ININCA.UBA-CONICET. Buenos Aires, Argentina Marcelo T. de Alvear 2270, C1122, Buenos Aires, Argentina; Tel/Fax: +5411 52852760;

E-mail: fcapani@fmed.uba.ar substances to reduce their chemical reactivity, free radical inhibitors, and scavengers [5]. However, no neuroprotective agent has been proved safe and effective in protecting ischemic-insult neonates from neurological sequels. It urges deepening our insight into biochemical and cellular mechanisms of neuronal injury induced by perinatal asphyxia to identify potential therapeutic targets and compounds [15].

Thioredoxin (Trx) family members are small proteins typically bearing the unique Trx folding and the cysteine-containing active site motif, crucial for electron transfer and oxidoreductase activity $[16,17]$. Thioredoxins and glutaredoxins (Grx) were first identified as electron donors to ribonucleotide reductase, and later described as cellular antioxidants protecting cells from reactive oxygen species-induced cell death. Peroxiredoxins (Prx), involved in peroxide decomposition, were identified as one of the major cellular peroxidases [16]. Currently, the thioredoxin family is recognized as comprising regulatory proteins crucially affecting protein function through oxidative post-translational changes or involved in the local and specific hydrogen peroxide degradation [17].

This study analyzes the expression and distribution of fourteen members of the Trx family, potentially essential for the regeneration upon long-term brain damage, in a perinatal hypoxia-ischemia rat model induced by a common carotid artery ligation.

\section{MATERIALS AND METHODS}

\subsection{Animals}

Pregnant Sprague-Dawley rats from the central bioterium of the School of Veterinary Sciences of the University of Buenos Aires were kept in a controlled environment at $21 \pm 2{ }^{\circ} \mathrm{C}$ and $65 \pm 5 \%$ humidity on a $12 \mathrm{~h}$ light-dark cycle (lights on at 8 a.m.) with free access to Purina chow food and tap water. The experiments were conducted according to the principles of the Guide for the Care and Use of Laboratory Animals (NIH Publications No. 80-23, revised 1996), and approved by the Institutional Animal Care and Use 
Committee at the School of Medicine of the University of Buenos Aires. All efforts were made to reduce the number of animals used and minimize suffering.

\subsection{Common Carotid Artery Ligation Procedure}

On day seven after birth (P7), male offsprings were i.p. anesthetized with ketamine $40 \mathrm{mg} / \mathrm{kg}$-xylazine $4 \mathrm{mg} / \mathrm{kg}$, and placed on a heat plate to keep body temperature constant at $37{ }^{\circ} \mathrm{C}$. The right common carotid artery (CCA) was exposed by an incision on the right side of the neck, isolated from nerve and vein, and permanently ligated with 6-0 surgical silk (Carotid group). After wound suture, the animals were placed back to their cages for 4-5 h. After recovery, the pups were placed in a stoppered $1 \mathrm{~L}$ glass jar partially submerged in a $37{ }^{\circ} \mathrm{C}$ water bath for thermal constancy, and exposed to $100 \% \mathrm{~N}_{2}\left(3 \mathrm{~L} / \mathrm{min} \mathrm{N}_{2}\right.$ flow) for $3 \mathrm{~min}$ to induce anoxia. Sham-surgery rats (Sham) underwent right CCA surgical exposure only but no ligation or $\mathrm{N}_{2}$ exposure. Euthanasia was administered to all rats at 30,60 , and 90 days of age.

\subsection{Western Blotting and Enzyme-linked Immunosorbent As- say (ELISA)}

The expression pattern of fourteen Trx proteins was analyzed in the cerebellum, corpus striatum, and hippocampus using Western blot or in the case of Grx 2 by ELISA.

Western blot analysis was performed slightly modified from Godoy et al. (2011). Rat brains dissected after euthanasia by decapitation were homogenized in ice-cold cell lysis buffer $(10 \mathrm{mM}$ Tris/HCl, pH 7.4, $10 \mathrm{mM} \mathrm{NaCl}, 3 \mathrm{mM} \mathrm{MgCl} 2,0.1 \%$ NP-40 nonionic detergent), fast-frozen in liquid nitrogen and kept at $-20{ }^{\circ} \mathrm{C}$. For analysis, the samples were thawed on ice and centrifuged at $13,500 \mathrm{x} \mathrm{g}$ for $20 \mathrm{~min}$ at $4{ }^{\circ} \mathrm{C}$. After discarding the pellets, the supernatants were analyzed in 96-well plates for total protein concentration using the Bradford solution (Bio-Rad, Munich, Germany) and bovine serum albumin (BSA) as the standard in at least triplicates. Total protein $(10-20 \mu \mathrm{g})$ was diluted in sample buffer $(0.3 \mathrm{M}$ Tris $/ \mathrm{HCl}, \mathrm{pH} 7,50 \%$ glycerol, $5 \%$ SDS, $1 \mathrm{mM}$ EDTA, $0.1 \%$ bromphenol blue), and subjected to SDS-PAGE using the Novex minicell (Invitrogen, Carlsbad, CA, USA) with precast 4-20\% Precise gels (Pierce-Thermo Fisher). Protein was transferred to polyvinylidene difluoride membranes (Schleicher \& Schuell, Germany) following the manufacturer's instructions. Membranes blocked with $5 \%$ nonfat milk powder and $1 \%$ BSA in Tris-buffer saline containing $0.05 \%$ Tween 20 were incubated with specific primary antibodies at $4{ }^{\circ} \mathrm{C}$ overnight. Antigen-antibody complexes were stained using horseradish peroxidase (HRP)-coupled anti-rabbit antibody (Bio-Rad, Richmond CA, USA). Enhanced chemiluminescence was recorded using a gel documentation system from Intas (Göttingen, Germany). A specific sandwich ELISA technique allowed quantifying glutaredoxin-2 level as described by Lundberg et al. (2004) and Hanschmann et al. (2010). The source and generation of the antibodies used in this study are described by Godoy et al. (2011).

\subsection{Immunohistochemistry}

Immunohistochemistry analysis was performed as described by Aon-Bertolino et al. (2011) and Godoy et al. (2011) with slight modifications. Animals were anesthetized with $0.1 \mathrm{~mL}$ of a $28 \%$ $\mathrm{w} / \mathrm{v}$ chloral hydrate solution/100 g body weight, and intracardially perfused with $4 \%$ paraformaldehyde (Sigma-Aldrich, St. Louis, MO, USA) freshly prepared in phosphate buffer $0.1 \mathrm{M}, \mathrm{pH} 7.4$. Following brain dissection and a 2-h fixation in 4\% paraformaldehyde solution, coronal sections ( $40 \mu \mathrm{m}$ thick) cut on an Oxford vibratome for light microscopy were incubated with $3 \%$ hydrogen peroxide for $10 \mathrm{~min}$ to quench endogenous peroxidases. After a 3step PBS washing, nonspecific antibody binding sites were blocked with 10\% normal goat serum (Invitrogen Corporation, Camarillo, CA, USA) in PBS, and sections were incubated overnight with the primary antibodies at $4{ }^{\circ} \mathrm{C}$. After the 3 -step PBS washing and room temperature incubation with a biotinylated secondary antibody (Vector Laboratories Inc., Burlingame, CA, USA) for $60 \mathrm{~min}$, the Extravidin-Peroxidase detection system (Sigma-Aldrich, St. Louis, MO, USA) was used for antigen staining following the manufacturer's recommendations. Sections were incubated at room temperature with the substrate Diaminobenzidine (Sigma-Aldrich, St. Louis, MO, USA) for 5 min, mounted with Canada balsam (SigmaAldrich, St. Louis, MO, USA), and were examined by light microscopy using a Leitz Laborlux S microscope (Heidelberg, Germany) equipped with a CCD video camera (Canon). Images were analyzed and compiled using Adobe Photoshop 11.0 CS4.

\subsection{Statistical Analysis}

Western-blot bands intensity was quantified using Gel-Pro ${ }^{\circledR}$ Analyzer 3.1 and expressed as the percentage of that observed in sham-operated rats. Results were expressed as the mean \pm SEM of at least four independent determinations of 6 sham-operated or 8 CCA-ligation rats. Between-group differences in biochemical parameters and protein levels were analyzed using the two-tailed Student's t-test. The level of significance was conventionally set at 5 $\%$. All analyses were performed using SPSS 15.0 (Chicago, IL, USA).

\section{RESULTS}

\subsection{Changes in Protein Expression Following Ischemia- Reperfusion}

Figs. (1) and (6) illustrate the expression pattern of the fourteen Trx family proteins in the cerebellum, corpus striatum, and hippocampus.

Thirty-day-old rats with CCA ligation showed an increase in Prx 2 and Trx 1 in the cerebellum and corpus striatum, respectively (Fig. 2a). Rats with CCA ligation 60 days old showed decreased expression of Prx 2 and Grx 5 in the cerebellum, and also in the corpus striatum for the former (Fig. 2b). The expression of Trx 2 and Grx2 increased in the hippocampus and the latter in the cerebellum as well (Figure 2 b). On post-natal day 90, the Grx5 protein level increased in the cerebellum, and Prx2 and TrxR1 expressions decreased in the hippocampus and corpus striatum, respectively (Fig. 2c).

\subsection{Distribution of the Trx family and related proteins in the cerebellum, hippocampus and corpus striatum}

In agreement with western blot analyses, Trx 1 staining increased in cellular bodies of the dorsal striatum (Fig. 3a) and the CA1 region of the hippocampus in 30-day old rats with CCA ligation (Fig. 4b) and conversely decreased in the axons of the CA1 pyramidal cells as compared with the sham-operated group. Both rat groups showed Prx2 cytosolic distribution in the cerebellum with increased immunoreactivity in the axonal projections of Purkinje cells in 30-day old rats with CCA ligation (Fig. 3c).

Sixty-day-old rats with CCA ligation showed a higher number of Grx2-immunostained cellular bodies in both the hippocampus and cerebellum (Figs. 4a and $\mathbf{4 b}$ ). Similarly, a higher number of Trx2-positive cellular bodies (Fig. 4c) and potential astrocytes (Fig. 4c, insert) were observed in the hippocampus in 60-day old rats with CCA ligation as compared with sham-operated rats. While all 60-day-old rats showed sustained Prx2 cytosolic distribution, Prx2 immunoreactivity decreased in the corpus striatum and cerebellum in rats with CCA ligation as compared with the sham-operated group (Figs. 4d and 4e).

Notwithstanding the increase in nuclear Prx2 immunostaining found in 90-day-old rats with CCA ligation (Fig. 5a), a decrease was observed in the CA1 area of the hippocampus as compared with their sham-operated counterparts. Similarly, nuclear Grx5 immunostaining increased in the cerebellum Purkinje layer in 90day-old rats with CCA ligation (Fig. 5b). At the same time, TrxR1 


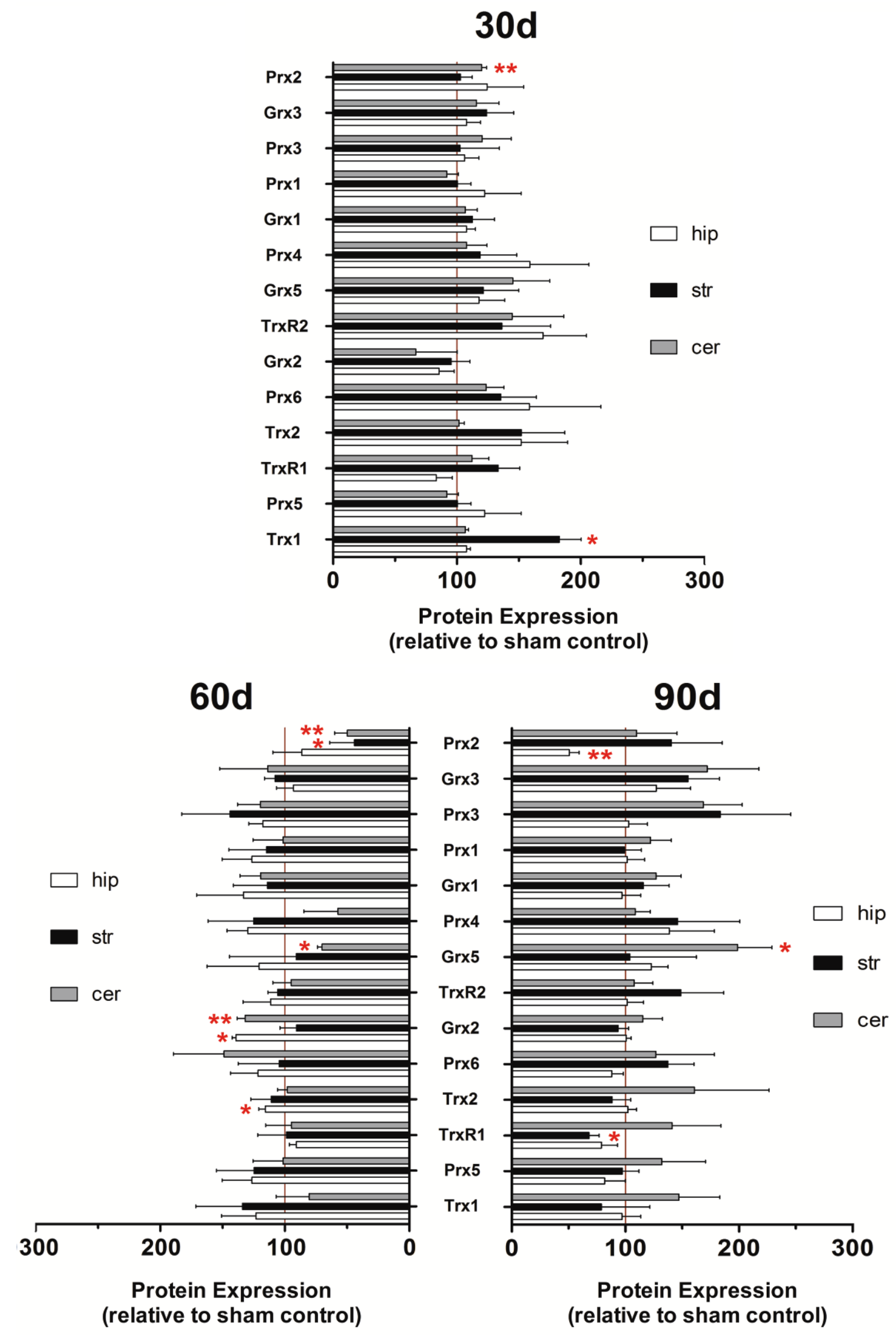

Fig. (1). Expression of thioredoxins and related proteins in CCA-ligation rats $(n=8)$ and sham-operated $(n=6)$ rats.

The hippocampus (hip), corpus striatum (str), and cerebellum (cer) were isolated and analyzed for protein expression using Western blot, or a specific sandwich ELISA for Grx2. The diagram depicts protein expression as the relative percentage of that observed in sham-operated rats. Values represent the mean \pm SEM. $* \mathrm{p} \leq 0.05$. (A higher resolution / colour version of this figure is available in the electronic copy of the article). 

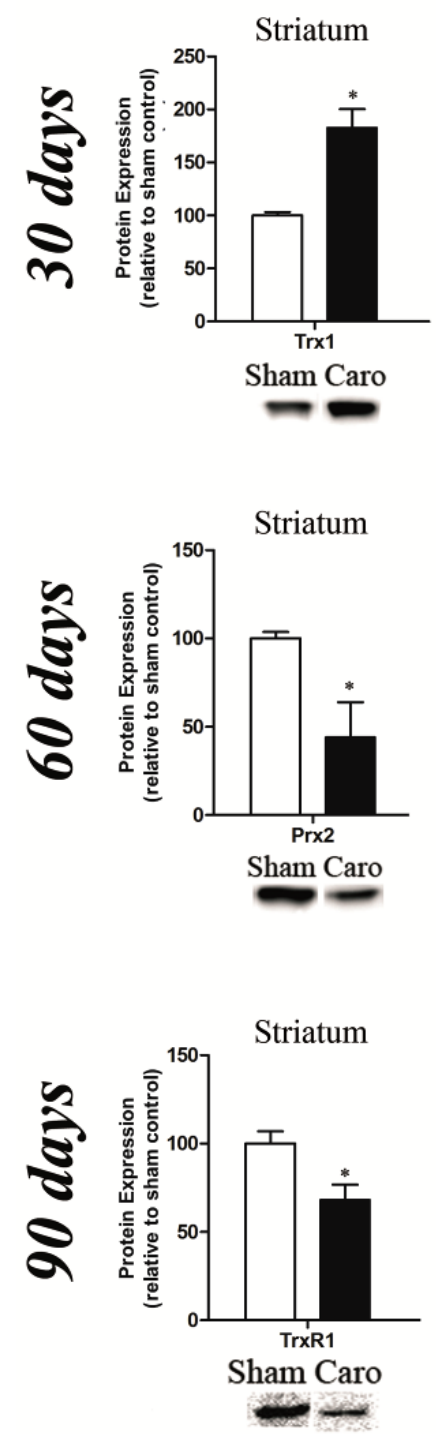
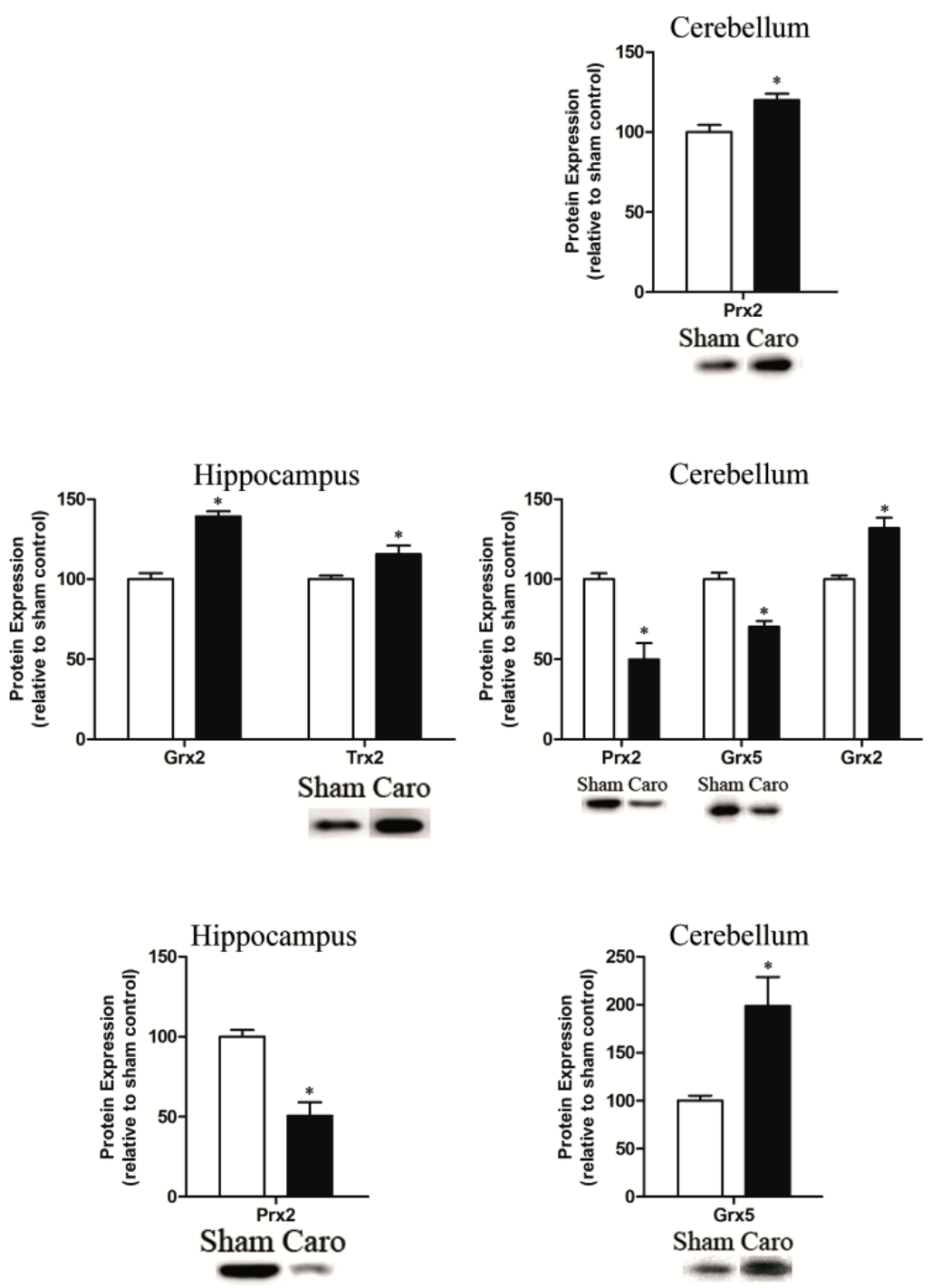

Fig. (2). Distinctive expression pattern of specific redoxins in CCA-ligation rats $(\mathrm{n}=8)$ and control sham-operated rats $(\mathrm{n}=6)$ overtime after the ischemic insult. (b) striatum (left) and cerebellum (right) at 30 days of age; (c) striatum (left), hippocampus (middle) and cerebellum (right) at 60 days of age; (d) striatum (left), hippocampus (middle) and cerebellum (right) at 90 days of age. Protein expression is shown as the relative percentage to that observed in sham-operated rats. Representative Western blots are also illustrated. Values represent the mean \pm SEM of 5 independent determinations at least. * $\mathrm{p} \leq 0.05$. (A higher resolution / colour version of this figure is available in the electronic copy of the article).

Trx1
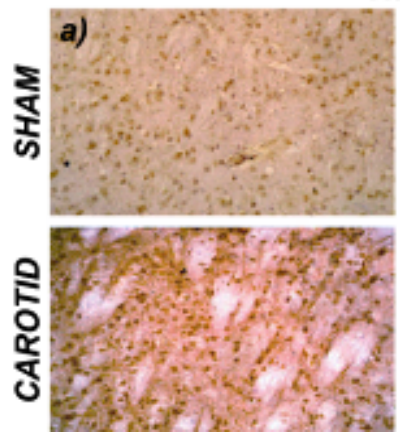
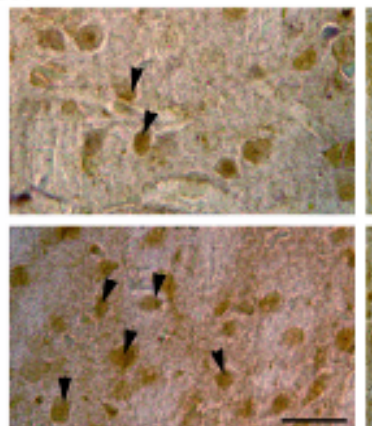

Trx1
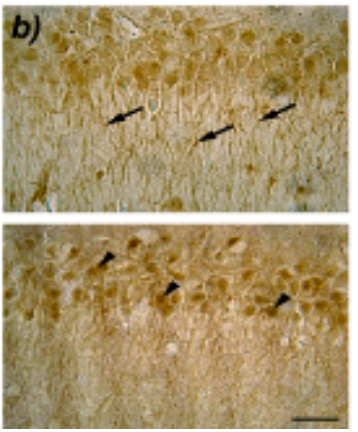

Prx2

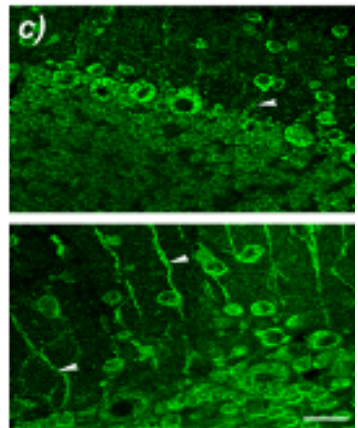

Fig. (3). Immunohistochemical analysis of the expression pattern of the thioredoxins family of proteins in sham-operated (n=6) and CCA-ligation (n=6) 30-day old rats.

a) Trx1 representative pictures of dorsal striatum: arrowheads show an increase in the number of immunopositive positive cellular bodies; b) Trx1 representative pictures of the CA1 area of the hippocampus: arrowheads show the change in immunopositive cellular bodies in CCA-ligation rats, whereas arrows show the large increase in immunopositive pyramidal cells projections in sham-operated rats; c) Prx 2 representative pictures of the cerebellum: disruption of the Purkinje cell layer is observed in the CCA-ligation group (bottom panel), arrowheads show a large increase in immunopositive axonal projections of Purkinje cells in CCA-ligation rats. Scale bar: $50 \mu \mathrm{m}$. (A higher resolution / colour version of this figure is available in the electronic copy of the article). 
Grx2

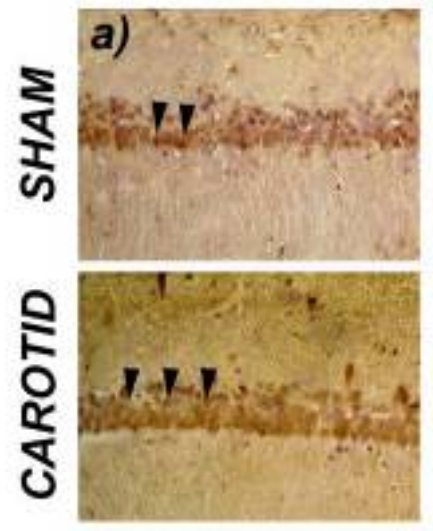

$\operatorname{Trx2}$
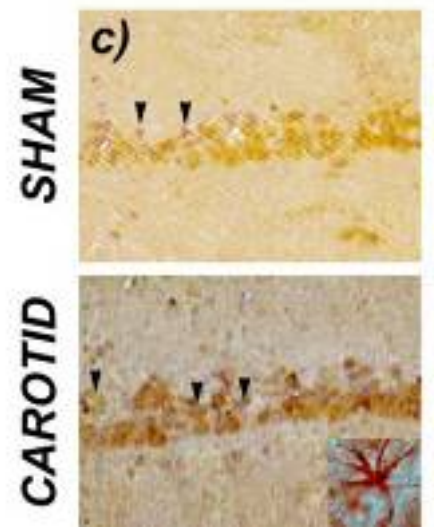
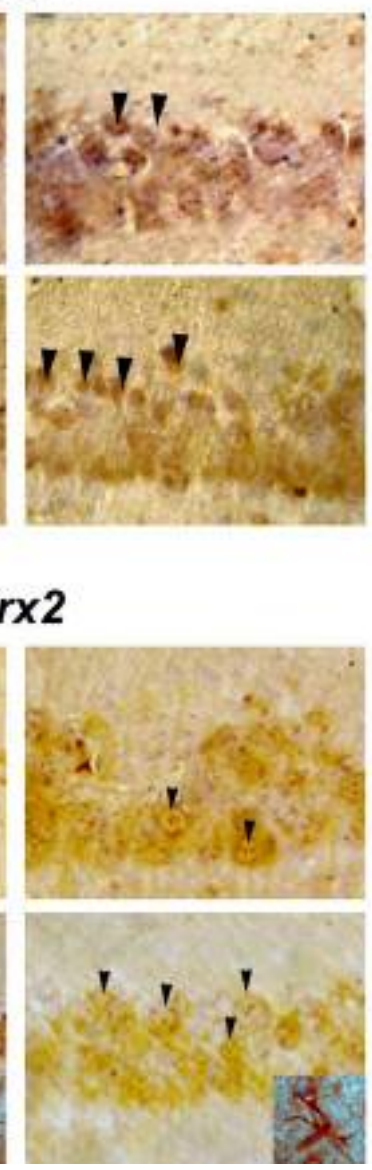

Grx2
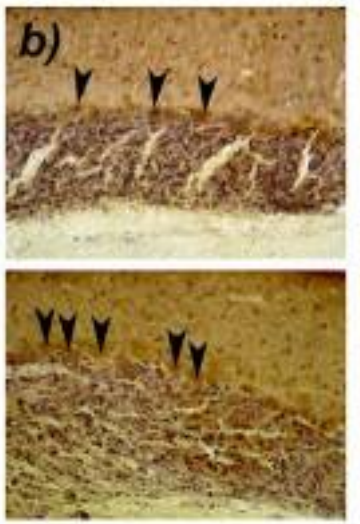

Prx2
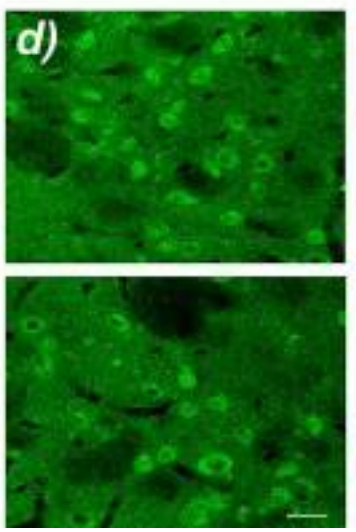

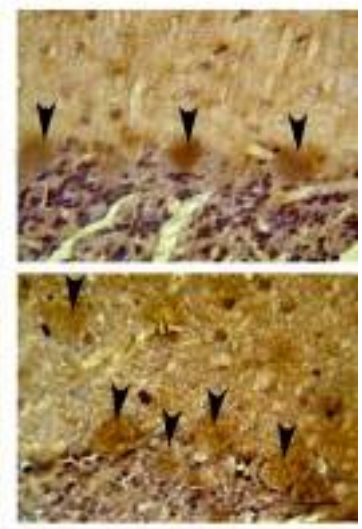

Prx2
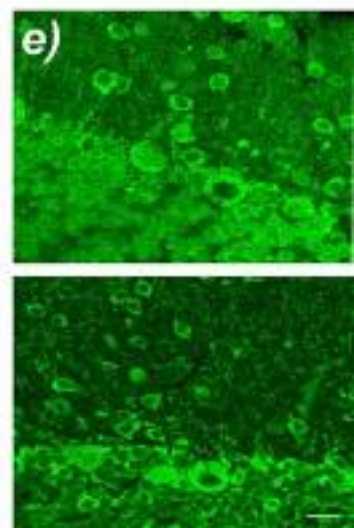

Fig. (4). Immunohistochemical analysis of thioredoxins expression in sham-operated $(n=6)$ and CCA-ligation $(n=6)$ rats 60 days after the ischemic insult. a) Grx2 immunostaining in the CA1 area of the hippocampus: arrowheads indicate an increased number of immunopositive cellular bodies in CCA-ligation rats; b) Grx2 localization in the cerebellum: arrowheads show an increased number of immunopositive cellular bodies and Purkinje cell layer is disrupted in CCA-ligation rats; c) Trx2 expression pattern in the CA1 area of the hippocampus: arrowheads show an increased number of immunopositive cellular bodies in CCA-ligation rats, which bear a strong immunoreactivity in what appear to be astrocytes (Insert); d) Prx2 representative pictures in the striatum: cytosolic distribution is observed in both rat groups; e) Prx2 localization in the cerebellum: immunopositivity is decreased in the granular layer in CCA-ligation rat. Scale bar: $50 \mu \mathrm{m}$. (A higher resolution / colour version of this figure is available in the electronic copy of the article).
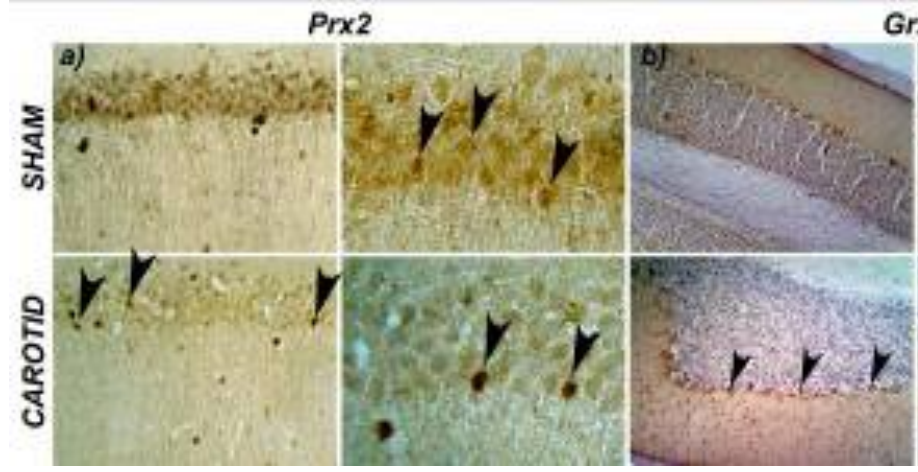

Grx5

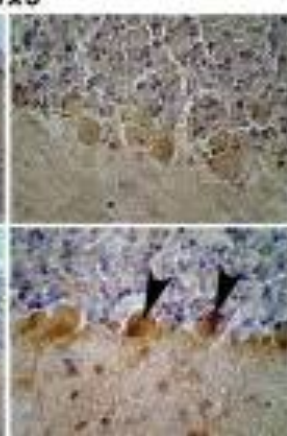

TrxR1

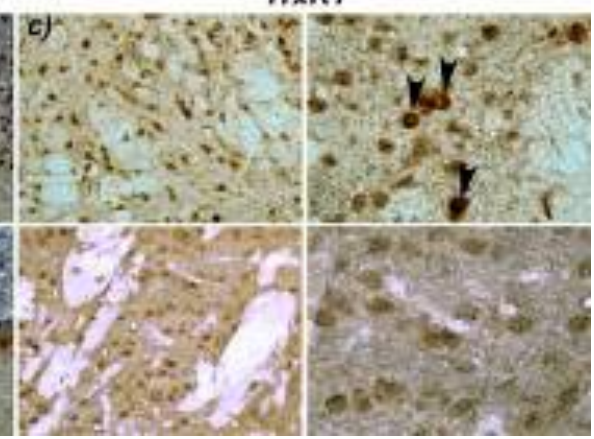

Fig. (5). Immunohistochemical analysis of the expression pattern of thioredoxin family of proteins in sham-operated ( $\mathrm{n}=6$ ) and CCA-ligation ( $\mathrm{n}=6$ ) rats 90 days after the ischemic insult.

a) Prx2 representative pictures from CA1 area of the hippocampus: arrowheads show an increased number of immunopositive cellular bodies in the CCAligation group regardless of the overall immunostaining decrease; b) Grx5 representative pictures from the cerebellum: arrowheads show an increase in nuclear staining in the Purkinje cell layer in CCA-ligation rats; c) TrxR1 representative pictures from the striatum: arrowheads show an increase in immunopositive cellular bodies in the sham-operated group. Scale bar: $50 \mu \mathrm{m}$.

Bar diagrams depict the mean of at least four independent measures in sham-operated $(\mathrm{n}=6)$ and CCA-ligation $(\mathrm{n}=8)$ animals \pm SEM. $($ A higher resolution $/$ colour version of this figure is available in the electronic copy of the article). 


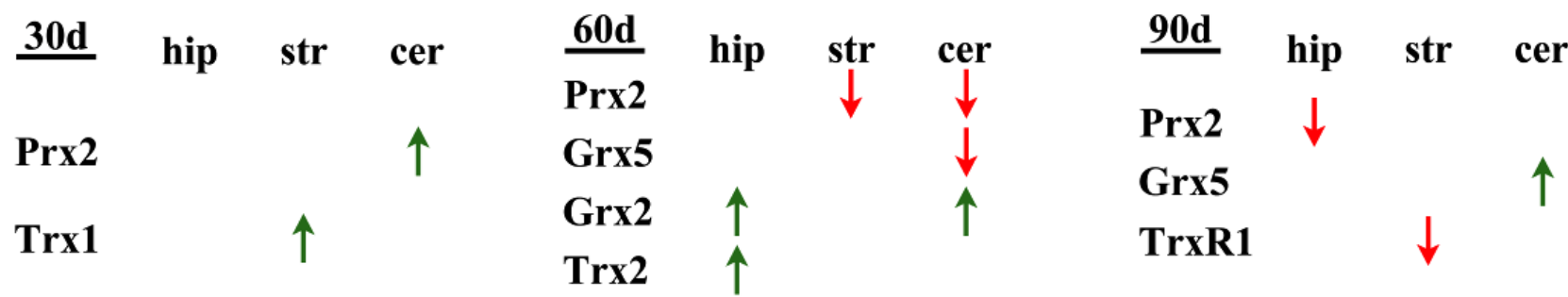

Fig. (6). Differential expression of thioredoxins in the brain of CCA-ligation rats. (A higher resolution / colour version of this figure is available in the electronic copy of the article).

nuclear immunostaining decreased in the dorsal striatum in 90-dayold rats with CCA ligation (Fig. 5c).

\section{DISCUSSION}

Reperfusion following an ischemic event boosts free radicals production with ensuing oxidative stress $[18,19]$, which has been consistently presumed as an important cause of ische$\mathrm{mia} /$ reperfusion-induced neuronal death [11, 19-21].

Previously, we reported the complex expression pattern of thioredoxins and related proteins in the rat central nervous system (CNS) [22]. It confirmed tissue- and cell type-specific distribution of these proteins, as an expression of specific functions and family members' complex crosstalk (Fig 6).

Presently, we examined the expression and distribution of 14 proteins of the thioredoxin family in a murine model of perinatal asphyxia aiming to analyze and understand their specific role in the immediate and long-term effects triggered by a hypoxic insult. We observed complex tissue-specific changes in the expression and distribution of distinct proteins following oxygen deprivation. Interestingly, the analyzed proteins seemed differently affected, depending on the time elapsed after the hypoxic insult. Although there are no available reports on Trx family proteins in perinatal asphyxia, both NO (nitric oxide) and ROS release has been implicated in this condition [11], potentially leading to redox signaling dysregulation, which might be responsible for inducing apoptosis in the CNS and long-term neurological deficits. Much like perinatal asphyxia pathology, redox control disruption or overall ROS generation $[13,14]$ by mitochondrial chain uncoupling [23] and inflammation $[24,25]$ were described as the key destructive downstream mechanisms underlying ischemia/reperfusion injury.

Our study shows sustained Trx 1 expression as late as 30 days after ischemia/reperfusion (Fig. 1). Notwithstanding severe hypoxia effects on cytosolic antioxidant Trx 1 expression in the brain have been shown in preconditioned rats $24 \mathrm{~h}$ and $72 \mathrm{~h}$ after reperfusion $[17,26,27]$, no study has been conducted on CNS long-term alterations. The increased expression of Grx 2 lasts for as long as 60 days after ischemia/reperfusion in the CCA ligated rats (Fig. 1). Oxidoreductase expression induction was also observed in a renal ischemia/reperfusion injury model [28]. Glutaredoxin 2 was overly expressed in proximal tubule cells, which can recover after an ischemic insult. Hypoxia-reoxygenation exposed HEK293, and HeLa cells overexpressing Grx2 showed less oxidative damage and increased survival and proliferation rates as compared with the wild-type counterparts [28]. All in all, the Grx2 over-expression might represent the system's attempt to recovering from the hypoxic-ischemic insult. As well as the anti-apoptotic effect of ROSinducing drugs such as doxorubicin [17, 29], Grx2 has been recently proved essential for embryonic brain development [30]. Oxidoreductase-silenced Zebrafish typically showed overall neuronal loss due to apoptosis and lack of a developed axonal scaffold [30]. The findings suggest that these proteins could be involved in longterm regeneration of physiological redox signaling with the recovery of affected tissues.
Carotid artery ligation reduced Prx 2 expression in rats 60 and 90 days old. Peroxiredoxin 2 exhibited potent pro-survival effects in ischemic neurons by keeping Trx reduced [31]. Thereby, this reduction could be an effect of the depletion of the protein while maintaining the high levels of trx 1 expression.

The Trx family of proteins has been reported as contributing to early brain tolerance after stress exposure $[27,32]$. Here we report brain protection as long as 90 days after the insult. These changes presumably contributed to an adaptive response to the adverse conditions.

The superior brainstem, cerebellum, white matter and subcortical structures supplied by the distal branches of deep and superficial penetrating blood vessels, cerebral white matter between the major cerebral artery territories, the CA1 region of the hippocampus, and neocortical layers 3,5 , and 6 are some of the most hypoxiaischemia vulnerable brain areas [33-35]. The modified pattern of the Trx family protein expression found in the most vulnerable areas of the brain, particularly in the hippocampus and cerebellum endorses the idea of the therapeutic use of these proteins to counteract brain damage following an ischemia/reperfusion insult. Notwithstanding the beneficial effects of Trx administration in adult stroke models [36, 37] and the implication of several Trx family members in cell survival, proliferation, and regeneration processes $[38,39]$, to our knowledge, thioredoxins have not been so far tested in a neonatal model of asphyxia.

\section{CONCLUSION}

Present findings suggest that the Trx family of proteins might contribute to long-term survival and recovery supporting their therapeutic use to curtail ischemic brain oxidative damage following an ischemia/reperfusion insult. Characterization of ischemia/reperfusion oxidative brain damage and analysis of the involved mechanisms are required to understand the underneath processes triggered by ischemia/reperfusion and to what extent and in what way thioredoxins contribute to recovery from brain hypoxic stress.

\section{ETHICS APPROVAL AND CONSENT TO PARTICIPATE}

Not applicable.

\section{HUMAN AND ANIMAL RIGHTS}

No Animals/Humans were used for studies that are the basis of this research.

\section{CONSENT FOR PUBLICATION}

Not applicable.

AVAILABILITY OF DATA AND MATERIALS

Not applicable.

\section{FUNDING}

None. 


\section{CONFLICT OF INTEREST}

The authors declare no conflict of interest, financial or otherwise.

\section{ACKNOWLEDGEMENTS}

This work was supported by grants from the National Scientific and Technical Research Council (PIP 11420100100159, CONICET, Argentina), the University of Buenos Aires (UBACYT 20020090100118) and the Deutsche Forschungsgemeinschaft (SFB593-N01), and by the German Academic Exchange Service DAAD and MINCYT (PROALAR program). Juan Ignacio Romero is a fellowship holder at the National Scientific and Technical Research Council (CONICET, Argentina). We thank Sabrina Oesteritz for excellent technical assistance.

\section{REFERENCES}

[1] Nelson KB, Grether JK. Potentially asphyxiating conditions and spastic cerebral palsy in infants of normal birth weight. Am J Obstet Gynecol 1998; 179(2): 507-13.

[http://dx.doi.org/10.1016/S0002-9378(98)70387-4] [PMID: 9731861]

[2] Paneth N. The causes of cerebral palsy. Recent evidence. Clin Invest Med 1993; 16(2): 95-102. [PMID: 8513618]

[3] Rice JE III, Vannucci RC, Brierley JB. The influence of immaturity on hypoxic-ischemic brain damage in the rat. Ann Neurol 1981; 9(2): 131-41.

[http://dx.doi.org/10.1002/ana.410090206] [PMID: 7235629]

[4] Titomanlio L, Kavelaars A, Dalous J, et al. Stem cell therapy for neonatal brain injury: perspectives and challenges. Ann Neurol 2011; 70(5): 698-712.

[http://dx.doi.org/10.1002/ana.22518] [PMID: 22162055]

[5] McGuire W. Perinatal asphyxia. BMJ clinical evidence 2007.

[6] Levine S. Anoxic-ischemic encephalopathy in rats. Am J Pathol 1960; 36: 1-17.

[PMID: 14416289]

[7] López-Aguilera F, Plateo-Pignatari MG, Biaggio V, Ayala C, Seltzer AM. Hypoxic preconditioning induces an AT2-R/VEGFR2 (Flk-1) interaction in the neonatal brain microvasculature for neuroprotection. Neuroscience 2012; 216: 1-9.

[http://dx.doi.org/10.1016/j.neuroscience.2012.04.070] [PMID: 22569153]

[8] Taniguchi H, Andreasson K. The hypoxic-ischemic encephalopathy model of perinatal ischemia. JoVE 2008.

[http://dx.doi.org/10.3791/955]

[9] Wang Y, Cheung PT, Shen GX, et al. Hypoxic-ischemic brain injury in the neonatal rat model: relationship between lesion size at early MR imaging and irreversible infarction. AJNR Am J Neuroradiol 2006; 27(1): 51-4.

[PMID: 16418355]

[10] Vannucci RC, Vannucci SJ. Perinatal hypoxic-ischemic brain damage: evolution of an animal model. Dev Neurosci 2005; 27(2-4): $81-6$

[http://dx.doi.org/10.1159/000085978] [PMID: 16046840]

[11] Capani F, Loidl CF, Aguirre F, et al. Changes in reactive oxygen species (ROS) production in rat brain during global perinatal asphyxia: an ESR study. Brain Res 2001; 914(1-2): 204-7. [http://dx.doi.org/10.1016/S0006-8993(01)02781-0]

[PMID: 11578613]

[12] Shalak L, Perlman JM. Hypoxic-ischemic brain injury in the term infant-current concepts. Early Hum Dev 2004; 80(2): 125-41.

[http://dx.doi.org/10.1016/j.earlhumdev.2004.06.003] [PMID: 15500993]

[13] Bonventre JV, Weinberg JM. Recent advances in the pathophysiology of ischemic acute renal failure. J Am Soc Nephrol 2003; 14(8): 2199-210.

[http://dx.doi.org/10.1097/01.ASN.0000079785.13922.F6] [PMID: 12874476]

[14] Wardle EN. Cellular oxidative processes in relation to renal disease. Am J Nephrol 2005; 25(1): 13-22.

[http://dx.doi.org/10.1159/000083477] [PMID: 15668522]

[15] Lai MC, Yang SN. Perinatal hypoxic-ischemic encephalopathy. J Biomed Biotechnol 2011; 2011609813 [http://dx.doi.org/10.1155/2011/609813] [PMID: 21197402]

[16] Holmgren A. Thioredoxin and glutaredoxin systems. J Biol Chem 1989; 264(24): 13963-6.

[PMID: 2668278]

[17] Lillig $\mathrm{CH}$, Holmgren A. Thioredoxin and related molecules--from biology to health and disease. Antioxid Redox Signal 2007; 9(1): 25-47.

[http://dx.doi.org/10.1089/ars.2007.9.25] [PMID: 17115886]

[18] Flamm ES, Demopoulos HB, Seligman ML, Poser RG, Ransohoff J. Free radicals in cerebral ischemia. Stroke 1978; 9(5): 445-7. [http://dx.doi.org/10.1161/01.STR.9.5.445] [PMID: 705824]

[19] Phillis JWA. A "radical" view of cerebral ischemic injury. Prog Neurobiol 1994; 42(4): 441-8.

[http://dx.doi.org/10.1016/0301-0082(94)90046-9]

[PMID: 8090929]

[20] Alonso-Alconada D, Hilario E, Álvarez FJ, Álvarez A. Apoptotic cell death correlates with ROS overproduction and early cytokine expression after hypoxia-ischemia in fetal lambs. Reprod Sci 2012 ; 19(7): 754-63.

[http://dx.doi.org/10.1177/1933719111432868] [PMID: 22378862]

[21] Buonocore G, Perrone S, Bracci R. Free radicals and brain damage in the newborn. Biol Neonate 2001; 79(3-4): 180-6. [http://dx.doi.org/10.1159/000047088] [PMID: 11275648]

[22] Aon-Bertolino ML, Romero JI, Galeano P, et al. Thioredoxin and glutaredoxin system proteins-immunolocalization in the rat central nervous system. Biochim Biophys Acta 2011; 1810(1): 93-110. [http://dx.doi.org/10.1016/j.bbagen.2010.06.011]

[PMID: 20620191]

[23] Baines CP. The mitochondrial permeability transition pore and ischemia-reperfusion injury. Basic Res Cardiol 2009; 104(2): 1818 [http://dx.doi.org/10.1007/s00395-009-0004-8] [PMID: 19242640]

[24] Hutchens MP, Dunlap J, Hurn PD, Jarnberg PO. Renal ischemia: does sex matter? Anesth Analg 2008; 107(1): 239-49.

[http://dx.doi.org/10.1213/ane.0b013e318178ca42]

[PMID: 18635495]

[25] Weight SC, Bell PR, Nicholson ML. Renal ischaemia--reperfusion injury. Br J Surg 1996; 83(2): 162-70.

[http://dx.doi.org/10.1002/bjs.1800830206] [PMID: 8689154]

[26] Stroev SA, Tjulkova EI, Gluschenko TS, Rybnikova EA, Samoilov MO, Pelto-Huikko M. The augmentation of brain thioredoxin-1 expression after severe hypobaric hypoxia by the preconditioning in rats. Neurosci Lett 2004; 370(2-3): 224-9.

[http://dx.doi.org/10.1016/j.neulet.2004.08.022] [PMID: 15488327]

[27] Stroev SA, Tyul'kova EI, Glushchenko TS, Tugoi IA, Samoilov MO, Pelto-Huikko M. Thioredoxin-1 expression levels in rat hippocampal neurons in moderate hypobaric hypoxia. Neurosci Behav Physiol 2009; 39(1): 1-5.

[http://dx.doi.org/10.1007/s11055-008-9091-5] [PMID: 19089634]

[28] Godoy JR, Oesteritz S, Hanschmann EM, Ockenga W, Ackermann W, Lillig CH. Segment-specific overexpression of redoxins after renal ischemia and reperfusion: protective roles of glutaredoxin 2, peroxiredoxin 3, and peroxiredoxin 6. Free Radic Biol Med 2011; 51(2): 552-61.

[http://dx.doi.org/10.1016/j.freeradbiomed.2011.04.036] [PMID: 21586322]

[29] Enoksson M, Fernandes AP, Prast S, Lillig CH, Holmgren A, Orrenius $\mathrm{S}$. Overexpression of glutaredoxin 2 attenuates apoptosis by preventing cytochrome c release. Biochem Biophys Res Commun 2005; 327(3): 774-9.

[http://dx.doi.org/10.1016/j.bbrc.2004.12.067] [PMID: 15649413]

[30] Bräutigam L, Schütte LD, Godoy JR, et al. Vertebrate-specific glutaredoxin is essential for brain development. Proc Natl Acad Sci USA $2011 ; 108(51): 20532-7$.

[http://dx.doi.org/10.1073/pnas.1110085108] [PMID: 22139372]

[31] Gan Y, Ji X, Hu X, et al. Transgenic overexpression of peroxiredoxin-2 attenuates ischemic neuronal injury via suppression of a redox-sensitive pro-death signaling pathway. Antioxid Redox Signal 2012; 17(5): 719-32.

[http://dx.doi.org/10.1089/ars.2011.4298] [PMID: 22356734]

[32] $\mathrm{Hu} \mathrm{X}$, Weng Z, Chu CT, et al. Peroxiredoxin-2 protects against 6hydroxydopamine-induced dopaminergic neurodegeneration via attenuation of the apoptosis signal-regulating kinase (ASK1) signaling cascade. J Neurosci 2011; 31(1): 247-61.

[http://dx.doi.org/10.1523/JNEUROSCI.4589-10.2011] [PMID 21209210] 
[33] Arbelaez A, Castillo M, Mukherji SK. Diffusion-weighted MR imaging of global cerebral anoxia. AJNR Am J Neuroradiol 1999; 20(6): 999-1007.

[PMID: 10445435]

[34] Busl KM, Greer DM. Hypoxic-ischemic brain injury: pathophysiology, neuropathology and mechanisms. NeuroRehabilitation 2010; 26(1): 5-13.

[http://dx.doi.org/10.3233/NRE-2010-0531] [PMID: 20130351]

[35] Chalela JA, Wolf RL, Maldjian JA, Kasner SE. MRI identification of early white matter injury in anoxic-ischemic encephalopathy. Neurology 2001; 56(4): 481-5.

[http://dx.doi.org/10.1212/WNL.56.4.481] [PMID: 11222791]

[36] Hattori I, Takagi Y, Nakamura H, et al. Intravenous administration of thioredoxin decreases brain damage following transient focal cerebral ischemia in mice. Antioxid Redox Signal 2004; 6(1): 81-7. [http://dx.doi.org/10.1089/152308604771978372]

[PMID: 14713338]

[37] Ma YH, Su N, Chao XD, et al. Thioredoxin-1 attenuates postischemic neuronal apoptosis via reducing oxidative/nitrative stress. Neurochem Int 2012; 60(5): 475-83.

[http://dx.doi.org/10.1016/j.neuint.2012.01.029] [PMID: 22330043]

[38] Godoy JR, Funke M, Ackermann W, et al. Redox atlas of the mouse. Immunohistochemical detection of glutaredoxin-, peroxiredoxin-, and thioredoxin-family proteins in various tissues of the laboratory mouse. Biochim Biophys Acta 2011; 1810(1): 2-92.

[http://dx.doi.org/10.1016/j.bbagen.2010.05.006]

[PMID: 20682242]

[39] Tonge D, Chan K, Zhu N, et al. Enhancement of axonal regeneration by in vitro conditioning and its inhibition by cyclopentenone prostaglandins. J Cell Sci 2008; 121(Pt 15): 2565-77.

[http://dx.doi.org/10.1242/jcs.024943] [PMID: 18650498] 